\title{
A METHODOLOGY FOR ANALYZING WHOLE TREE LOGGING IN BULGARIA
}

\author{
J. Vasilev ${ }^{1 *}$, M. Kaneva ${ }^{2}$ \\ ${ }^{1}$ Department of Informatics, University of Economics - Varna, Bulgaria \\ ${ }^{2}$ Department of Statistics, University of Economics - Varna, Bulgaria
}

\begin{abstract}
The process of whole tree logging in Bulgaria is regulated by The Executive Forest Agency. This Agency provides information about the planned area and the planned quantity of tree logging for each municipality and each plot of land. It also keeps track of the real area and real quantity of tree logging by each plot of land. The purpose of this paper is to present a methodology for analyzing the whole tree logging process using public available data. Statistical methods such as correlation analysis, testing of hypotheses, analyzing growth rates and calculating structural change indexes are applied. Visual grouping of locations reveals three groups of places. It is proved that there is a great correlation between the planned area, planned quantity, the real area and the real quantity of tree logging for each year. Growth rate analysis gives signals for possible problems with tree logging. The structural change indexes show great variations in the structure of living places providing wood.
\end{abstract}

Key words: correlations, forestry, structural change index, growth rates

\section{INTRODUCTION}

Whole tree logging is an activity strictly regulated by law in Bulgaria. The Executive Forest Agency in Bulgaria gives licenses for whole tree logging (WTL). Information about issued licenses is public. Information about each license is available. There are different types of tree logging. They are not discussed in this article. This article describes a methodology for analyzing public data about tree logging. It should be marked that information about the type of wood and the purpose of the harvested wood is not available. To show the methodology for analyzing public data, one of the municipalities in Bulgaria Aksakovo is chosen. It is situated near Varna. The living places in the Aksakovo region are mainly in rural areas. But the proximity to a comparatively big town (Varna) means that a highly inhabited area is concentrated with many potential corporate customers as well as separate people needing wood for manufacturing or heating. The proximity of the municipality of Aksakovo to two resorts (Golden Sands and Albena) increases the set of potential customers. Tourism is well developed

\footnotetext{
*Correspondence to: $J$. Vasilev, Department of informatics, University of Economics - Varna, Bulgaria, e-mail: vasilev@ue-varna.bg
}

near these resorts. A lot of guest houses and private villas increase the need of wood. The existence of many customers may lead to illegal whole tree logging. Some indicators about it may be calculated using the proposed methodology.

Even though whole tree logging in Aksakovo region is not a typical business activity for this region, the proposed methodology may be used by other municipalities for analyzing whole tree logging. Since tree logging is regulated by different laws in other European countries, the proposed methodology needs to be changed in order to be applied in other countries.

Tree logging provides employment for many people in the rural area of many Bulgarian regions. The natural renovation of forests means that forests need time to recreate from wood cutting. This process is monitored by many organizations. Using public datasets we may check if the areas for real tree logging are different in different years in one and the same location. This is one of the initial research hypotheses that have to be checked. We assume that there are not significant differences between the planned area and the real area for WTL. We assume also that there are not significant differences between the 
planned quantities and the real quantities for WTL. All these research hypotheses are tested using approved statistical methods $(1,2)$.

The timber harvest depends on the type of wood, the climate and the politics for planting new trees. If new trees are planted and the level of the harvest is approximately to the growth of wood in the region, there will be no problems with the forests.

But problems concerning mass wood cutting and illegal wood cutting may lead to negative economic and environmental effects.

\section{LITERATURE REVIEW}

Whole tree logging is a topic discussed in many research articles and $\mathrm{PhD}$ theses. Possible aspects of optimization of tree logging in Bulgaria are studied by (3). The costbenefit-analysis is applied. Dichev has made a trend line in MS Excel, describing the growth rate of tree logging at a national level. He proves that the real quantities of tree logging in Bulgaria increase each year. The formal description of the increase is formalized by a polynomial function of the third degree $\left(\mathrm{R}^{2}=0.77\right)$. Information about tree logging is grouped in a Pivot table, showing real quantities of tree logging by regions (by rows) and years (by columns) from 2008 until 2012. A SWOT analysis of tree logging is given. A part of Dichev's research analyzes costs for tree logging.

A part of the previous research on whole tree logging analyzes the operational time and productivity in whole-tree and cut-to-length logging operation system (4). Another group of articles focuses on the illegal tree logging (5). Harvesting costs is another topic studied with tree logging (6). Sometimes GIS are used to monitor tree logging.

Some journals (e.g. Journal of Forest and Environmental Science, Agricultural and Forest Entomology, Agroforestry systems, American Forests, Annals of Forest Research, Australian Forestry, Baltic Forestry, Canadian Journal of Forest Research, Croatian Journal of Forest Engineering, Turkish Journal of Agriculture and Forestry, Forest Systems, International Forestry Review) are devoted to analyzing forestry.

Correlation analysis is a well-known statistical technique (7). It is used to find relationship among variables (8). Usually relationships have to be causal. The existence of a correlation among variables does not mean that there is causality. Sometimes possible dependencies are not obvious. In this case, it is recommended (9) to use both statistical (10) and artificial intelligence software (11) to test ambiguous dependencies.

Structural changes in farms are a discussed topic (12). These structural changes are studied by regions and by the purpose of each farm. Anastasova proves that growth rates cannot be used to describe structural changes. Structural changes should be analyzed at a regional level. Structural changes may be studied by many indicators (13). The choice of an appropriate indicator depends on the data that has to be analyzed (14).

Analyzing datasets may be done within spreadsheets (e.g. MS Excel) as well as within statistical software. Both software products are used by many researchers $(15,16,17)$.

\section{MATERIAL AND METHOD}

This study aims at analyzing the whole tree logging (WTL) in Aksakovo region in the period 2011-2015. The main source of data is the Agency giving licenses for woodcutting The Executive Forest Agency in Bulgaria (18). Each license contains information about the planned area and the planned quantity for woodcutting at a certain place. After the use of the license, wood cutters report information about the real area and the real quantities of cut wood. The Executive Forest Agency in Bulgaria provides values of individual cases (licenses). Information about thy type of harvested wood or the purpose of use is not available. We have made an aggregation of the public data for Aksakovo. Data from issued licenses is grouped by towns and villages in the Aksakovo region. We do not use confidential data. We use public data grouped by location. Using aggregated data by places and years and not looking at the type of tree logging and the purpose of harvested wood, comparability of data by years and locations is available.

Several research hypotheses are defined:

H1: There is a correlation between the planned area for woodcutting and the real area.

$\mathrm{H} 2$ : There is a correlation between the planned quantity of wood for woodcutting and the real quantity of harvested timber in the region.

H3: There is a correlation between the planned area for woodcutting and the planned quantity of harvested timber in the region. 
$\mathrm{H} 4$ : There is a correlation between the real area for woodcutting and the real quantity of harvested timber in the region.
These four hypotheses (Figure 1) have to be checked for each year $(2011,2012,2013,2014$ and 2015).

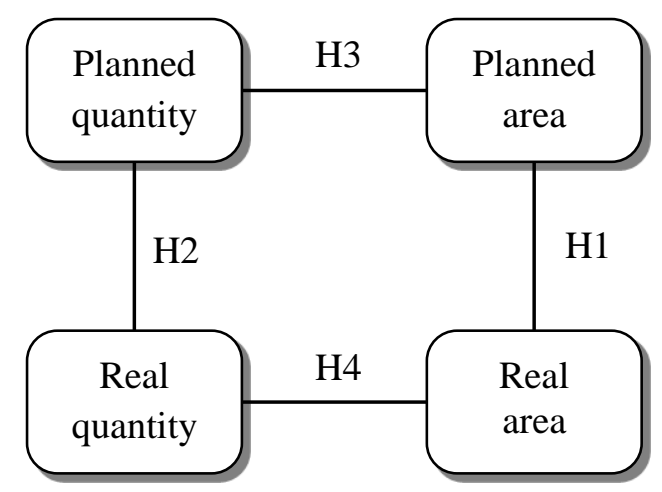

Figure 1. Initial hypotheses

Aggregated data is used. The Spearman's rank correlation coefficient is calculated.

The first step of the proposed methodology is grouping of data by years and living places. Data is grouped by years (columns) and living places (rows). The dataset (after aggregating data by living places /locations/) consists of 19 records. The small number of records in the dataset suggests the application of a small number of statistical techniques for analyzing it. That is why descriptive techniques, correlation analysis, growth rates and indexes of structural changes are used. Approved methods in practice are used - statistical methods. These methods are deferred with the small number of observations.

The harvest of timber depends on the type of timber, the climate and the politics for planting new trees. If new trees are planted and the level of the harvest is approximately to the growth of wood in the region, there will be no problems with the forests. There should not be a significant correlation (Figure 2) between the values of each year (H5, H6, H7 and H8).

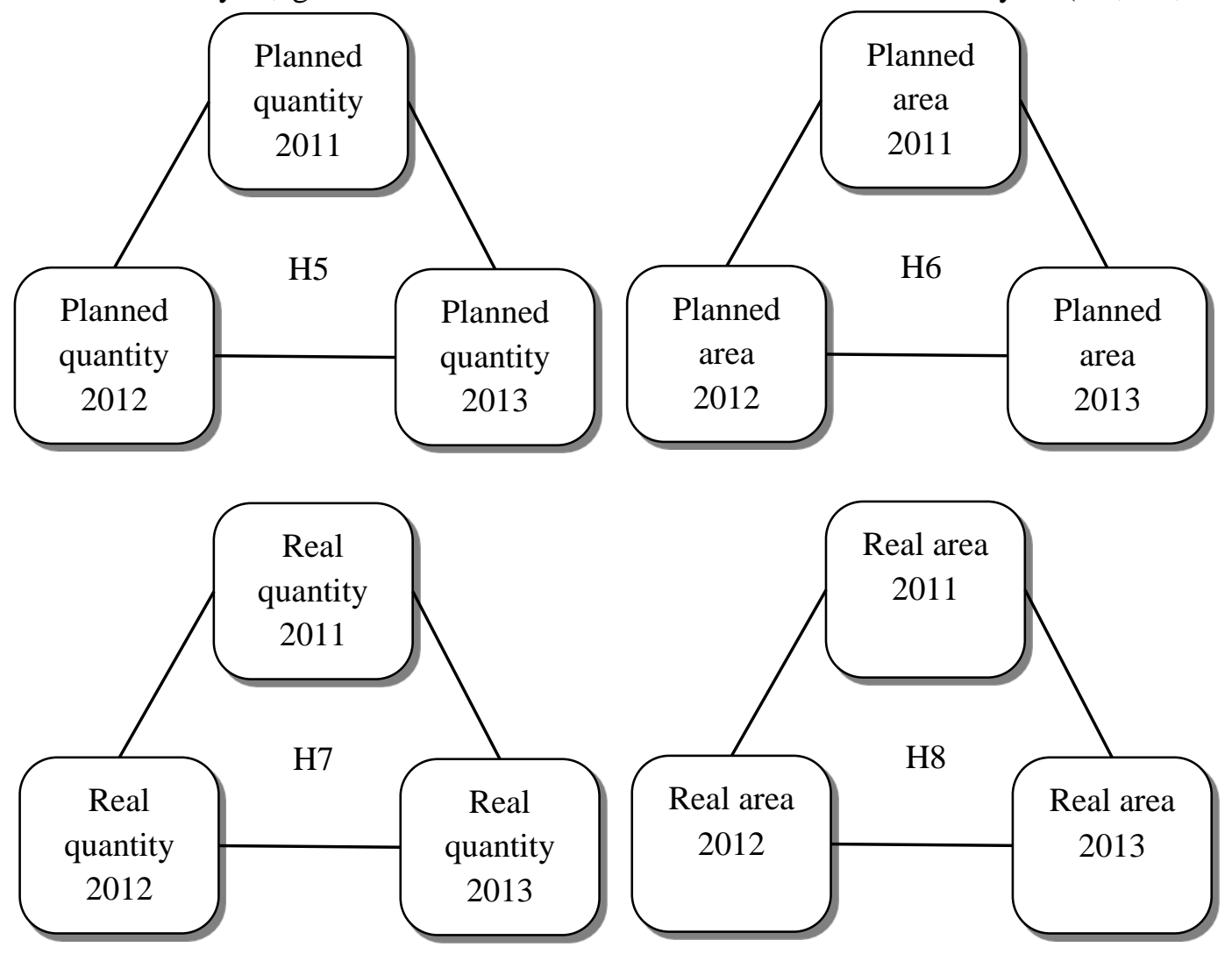

Figure 2. Second part of hypotheses 
Making groups of places will show municipalities with great quantities of tree logging and others with comparatively small quantities. If grouping by real quantities is impossible, the possible reason may be small variations in real quantities. This may not be a problem for rural regions but it may be stated as a problem for urban regions combined with rural ones.

Growth rates for each place for adjacent years are calculated. For planned quantities (PQ) the following growth rates are calculated: 20122011, 2013-2012, 2014-2013 and 2015-2014.
Growth rates for planned areas (PA), real quantities (RQ) and real areas (RA) by adjacent years are also calculated. Growth rates may show the possibility of constantly increasing or decreasing harvesting or areas in some places. If RQ>PQ some problems with illegal whole tree logging may exist.

The structural change index is used to find structural changes in real quantities.

\section{RESULTS AND DISCUSSION}

The result of testing the research hypotheses is given in the following table. The correlations are calculated within SPSS (Table 1).

Table 1. Correlations

\begin{tabular}{|l|l|r|r|}
\hline \multirow{5}{*}{ Hypothesis } & Tested variables & $\begin{array}{c}\text { Spearman's } \\
\text { rank } \\
\text { correlation } \\
\text { coefficient }\end{array}$ & Sig. (2-tailed) \\
\hline \multirow{5}{*}{ H1 } & PA2011-RA2011 & 0.967 & 0.000 \\
\cline { 2 - 4 } & PA2012-RA2012 & 0.978 & 0.000 \\
\cline { 2 - 4 } & PA2013-RA2013 & 0.889 & 0.000 \\
\cline { 2 - 4 } & PA2014-RA2014 & 0.912 & 0.000 \\
\cline { 2 - 4 } & PA2015-RA2015 & 0.930 & 0.000 \\
\hline \multirow{5}{*}{ H2 } & PQ2011-RQ2011 & 0.973 & 0.000 \\
\cline { 2 - 4 } & PQ2012-RQ2012 & 0.981 & 0.000 \\
\cline { 2 - 4 } & PQ2013-RQ2013 & 0.776 & 0.008 \\
\cline { 2 - 4 } & PQ2014-RQ2014 & 0.903 & 0.000 \\
\cline { 2 - 4 } & PQ2015-RQ2015 & 0.985 & 0.000 \\
\hline \multirow{5}{*}{ H3 } & PQ2011-PA2011 & 0.957 & 0.000 \\
\cline { 2 - 4 } & PQ2012-PA2012 & 0.776 & 0.000 \\
\cline { 2 - 4 } & PQ2013-PA2013 & 0.831 & 0.000 \\
\cline { 2 - 4 } & PQ2014-PA2014 & 0.945 & 0.000 \\
\cline { 2 - 4 } & PQ2015-PA2015 & 0.896 & 0.000 \\
\hline \multirow{5}{*}{} & RQ2011-RA2011 & 0.950 & 0.000 \\
\cline { 2 - 4 } & RQ2012-RA2012 & 0.832 & 0.000 \\
\cline { 2 - 4 } & RQ2013-RA2013 & 0.869 & 0.000 \\
\cline { 2 - 4 } & RQ2014-RA2014 & 0.945 & 0.000 \\
\cline { 2 - 4 } & RQ2015-RA2015 & 0.950 & 0.000 \\
\hline
\end{tabular}

Note: PA - planned area, RA - real area, PQ - planned quantity, RQ - real quantity.

There is a positive correlation between the tested variables. The four research hypotheses (H1, H2, H3 and H4) are accepted. Some remarks may be made. The values of the correlation coefficients increase during the studied five years. It means that people who ask for licenses for wood cutting do not overestimate or do not underestimate the area they plan to work on. The same may be concluded for the correlation (PQ-RQ). The differences between planned quantities and real quantities do not become greater. We may suppose that it is difficult to estimate the future harvest. The tested link between real quantities and real area (RQ-RA) shows that the correlation coefficients increase. It means that the discrepancies between areas and harvest become clearer. We may suppose that more timber is produced from smaller areas or more timber is produced from larger areas.

The correlation coefficients for the second part of research hypotheses are calculated within SPSS (Table 2).

We may conclude that we accept H5, H6, H7 and $\mathrm{H} 8$ - there are not correlations between the quantities and areas between different years. Areas which are planned for wood cutting are different for different years. The produced quantity of timber differs in each year. The forests may renovate.

The planned quantities and the planned area increase in 15 locations. The planned 
VASILEV J., et al.

quantities and the planned area decrease in 3 locations. There is one location with decrease in planned quantities and an increase in planned quantities. There are 12 locations where real quantities and real areas increase.
There are 4 places where real quantities and real areas decrease. There are two places with decrease in real quantities and increase in real area. There is one place with increase in real quantities and decrease in real area.

Table 2. Correlations - second part

\begin{tabular}{|l|l|r|r|}
\hline \multirow{4}{*}{ Hypothesis } & Tested variables & $\begin{array}{c}\text { Spearman's } \\
\text { rank } \\
\text { correlation } \\
\text { coefficient }\end{array}$ & Sig. (2-tailed) \\
\hline \multirow{3}{*}{ H5 } & PQ2011-PQ2012 & -0.555 & 0.823 \\
\cline { 2 - 4 } & PQ2012-PQ2013 & 0.294 & 0.222 \\
\cline { 2 - 4 } & PQ2011-PQ2013 & -0.164 & 0.503 \\
\hline \multirow{3}{*}{ H6 } & PA2011-PA2012 & -0.219 & 0.368 \\
\cline { 2 - 4 } & PA2012-PA2013 & 0.371 & 0.118 \\
\cline { 2 - 4 } & PA2011-PA2013 & 0.098 & 0.681 \\
\hline \multirow{3}{*}{ H8 } & RQ2011-RQ2012 & -0.053 & 0.829 \\
\cline { 2 - 4 } & RQ2012-RQ2013 & 0.252 & 0.297 \\
\cline { 2 - 4 } & RQ2011-RQ2013 & -0.079 & 0.746 \\
\cline { 2 - 4 } & RA2011-RA2012 & -0.216 & 0.375 \\
\cline { 2 - 4 } & RA2012-RA2013 & 0.296 & 0.219 \\
\cline { 2 - 4 } & RA2011-RA2013 & 0.226 & 0.352 \\
\hline
\end{tabular}

The first group of places contains 6 locations, the second one - one location and the third one -12 locations. The first group contains places with the lowest values of timber harvest (below 300 $\mathrm{m}^{3}$ ). The second group contains one village with no timber harvest in year 2015. The third group contains mainly places with comparatively high values of timber harvest (above $300 \mathrm{~m}^{3}$ ). We may conclude that there are great variations between the harvests among different villages. There are great variations among different years as well as among different places within one year.

Grouping may be done in any statistical software. Descriptive statistics shown above reveals three places with comparatively big amounts of real quantities. It is also obvious that several places have small real quantities.

Growth rates for PQ, PA, RQ and RA by places and adjacent years are calculated. Conditional formatting is used to illustrate variations of numbers among years and places (Table 3).

Table 3. Growth rates of real quantities (RQ) by places and adjacent years

\begin{tabular}{|l|r|c|c|r|}
\hline \multicolumn{1}{|c|}{ Place } & $\begin{array}{r}\text { 2012- } \\
\text { 2011 }\end{array}$ & $\begin{array}{c}\text { 2013- } \\
\text { 2012 }\end{array}$ & $\begin{array}{c}\text { 2014- } \\
2013\end{array}$ & $\begin{array}{c}2015- \\
2014\end{array}$ \\
\hline Aksakovo & 1.919 & 2.888 & 0.185 & 0.351 \\
\hline Botevo & 2.866 & 2.599 & 0.663 & 1.342 \\
\hline Voditza & 6.910 & 0.364 & 2.664 & 0.166 \\
\hline Vyglen & 0.325 & 0.997 & 1.730 & 0.018 \\
\hline G. Kantardzhievo & 5.465 & 0.203 & 3.859 & 1.452 \\
\hline Dobrogled & 0.000 & 0.049 & 0.000 & 0.000 \\
\hline Dolishte & 11.831 & 0.085 & 5.658 & 0.463 \\
\hline Zasmyano & 0.000 & 0.458 & 2.619 & 0.007 \\
\hline Zornitza & 3.020 & 0.384 & 0.327 & 0.000 \\
\hline Igantievo & 0.000 & 0.000 & 0.000 & 0.000 \\
\hline Izvorsko & 0.168 & 1.897 & 1.796 & 1.867 \\
\hline Kichevo & 13.891 & 0.583 & 0.315 & 1.319 \\
\hline Kliementovo & 0.000 & 0.000 & 9.050 & 0.000 \\
\hline Krumovo & 3.707 & 0.176 & 3.383 & 0.225 \\
\hline Kumanovo & 2.862 & 0.193 & 0.287 & 11.560 \\
\hline L. Karavelovo & 3.208 & 0.026 & 40.217 & 0.885 \\
\hline Novakovo & 0.981 & 4.682 & 0.156 & 3.966 \\
\hline Oreshak & 32.447 & 1.581 & 0.380 & 2.862 \\
\hline Osenovo & 0.000 & 0.000 & 0.000 & 3.468 \\
\hline
\end{tabular}


Conditional formatting and color scales are used in MS Excel. The colored table is particolored. It means that there is no place with a notification of a trend for increasing or decreasing of WTL during the analyzed period. Analogical tables are created for PQ, PA and RA by places and adjacent years but they are not given in this paper. These tables with growth rates may be analyzed in the same way.
Correlations between growth rates should not be calculated.

The last step of the proposed methodology of analyzing the dataset for the WTL consists of calculating the ratio between real quantities and planned quantities of growth rates by places and adjacent years. Conditional formatting with color scales is used again (Table 4) to find places with a possible existence of a trend (increasing or decreasing).

Table 4. Ratios between growth rates of real quantities $(R Q)$ and planned quantities $(P Q)$

\begin{tabular}{|l|r|r|r|r|}
\hline \multicolumn{1}{|c|}{ Place } & $2012-$ & $2013-$ & $2014-$ & $2015-$ \\
& 2011 & 2012 & 2013 & 2014 \\
\hline Aksakovo & 0.434 & 1.245 & 1.282 & 0.248 \\
\hline Botevo & 0.839 & 0.739 & 0.722 & 1.961 \\
\hline Voditza & 0.966 & 0.644 & 1.517 & 1.013 \\
\hline Vyglen & 1.032 & 0.826 & 1.159 & 1.028 \\
\hline G. Kantardzhievo & 1.183 & 0.158 & 5.087 & 1.017 \\
\hline Dobrogled & 0.000 & 1.079 & 0.000 & 0.000 \\
\hline Dolishte & 1.073 & 0.580 & 1.524 & 1.031 \\
\hline Zasmyano & 0.000 & 0.252 & 1.796 & 2.314 \\
\hline Zornitza & 1.210 & 1.280 & 1.101 & 0.000 \\
\hline Igantievo & 0.000 & 0.000 & 0.000 & 0.000 \\
\hline Izvorsko & 0.427 & 2.391 & 0.360 & 2.782 \\
\hline Kichevo & 1.081 & 0.908 & 0.619 & 1.454 \\
\hline Kliementovo & 0.000 & 0.000 & 3.671 & 0.000 \\
\hline Krumovo & 0.889 & 0.305 & 2.739 & 1.328 \\
\hline Kumanovo & 0.969 & 0.426 & 0.841 & 2.848 \\
\hline L. Karavelovo & 1.110 & 0.036 & 25.316 & 1.284 \\
\hline Novakovo & 1.004 & 1.000 & 0.449 & 1.359 \\
\hline Oreshak & 0.905 & 0.938 & 0.525 & 2.223 \\
\hline Osenovo & 0.000 & 0.000 & 0.000 & 1.166 \\
\hline
\end{tabular}

Values above 1 show that the growth rates of real quantities are greater that the growth rate of planned quantities. Places with values above 1 signal for possible problems with underestimation of tree logging. Places with values below 1 signal for possible problems with illegal tree logging.

The structural change index is calculated for adjacent years (Table 5).

Table 5. Structural change index

\begin{tabular}{|c|c|c|c|c|}
\hline \multirow{2}{*}{ Years } & $2012-$ & $2013-$ & $2014-$ & $2015-$ \\
& 2011 & 2012 & 2013 & 2014 \\
\hline SCI & 0.854 & 0.665 & 0.678 & 0.605 \\
\hline
\end{tabular}

The structural change indexes show that structural changes exist between adjacent years. This conclusion is another proof of the weak correlation dependency between real quantities in adjacent years. This structural change indexes show that the structure of places in their contribution to harvesting wood changes during the analyzed years.

\section{CONCLUSIONS}

This paper provides a methodology for analyzing tree logging in Bulgaria using available public data from the Executive Forest Agency. The proposed methodology for analyzing whole tree logging consists of several steps. The data analysis starts with aggregating data. A table for planned quantities by places (rows) and years (columns) is created. Analogical tables for planned area, real quantity and real areas are created. Growth rates for adjacent years are calculated. Conditional formatting is used to find possible problems. Ratios of growth rates of real quantities and planned quantities are calculated. Ratios of growth rates of planned quantities and planned areas are calculated. 
Conditional formatting is used again to find problems in some places.

To illustrate the methodology one of the Bulgarian municipalities is chosen. It is Aksakovo. Using the proposed methodology several inferences are bought out. There is a correlation between the planned area for woodcutting and the real area. There is a correlation between the planned quantity of wood for woodcutting and the real quantity of harvested timber in the region. There is a correlation between the planned area for woodcutting and the planned quantity of harvested timber in the region. There is a correlation between the real area for woodcutting and the real quantity of harvested timber in the region. People who ask for licenses for wood cutting usually do not overestimate or underestimate the area they plan to work on. There are not correlations between the quantities and areas between different years. Areas which are planned for wood cutting are different for each year. The produced quantity of timber differs in each year for each location. There are great variations between the harvests among different villages. We found out that there are also great variations among different years. Ratios between growth rates of real and planned quantities indicate the existence of problems concerned with illegal tree logging and underestimating the volume of tree logging.

By calculating structural change indexes we have shown that the structure of places in their contribution to harvesting wood changes during the analyzed years.

Future research may focus on making the same analysis for other municipalities in Bulgaria and other EU countries. Future research may deal with more detailed information of tree logging concerning the type of harvested wood and its purpose of use.

\section{REFERENCES}

1. Hadzhiev, V. et. al. Statistical and econometric software. Science and economics, Varna, 2009 (in Bulgarian).

2. Pallant, J. SPSS SURVIVAL MANUAL: A step by step guide to data analysis using SPSS. Allen and Unwin, 2011.

3. Dichev, P. A research of the economical effectiveness of tree logging in state forests. $\mathrm{PhD}$ thesis, 2014, http://www.ltu.bg/files/file/Fakulteti/SU/Do ctoranti/Pavel Dichev/Avtoreferat.pdf

4. Kim, M. K. and Park, S. J. An Analysis of the Operational Time and Productivity in Whole-tree and Cut-to-Length Logging Operation System. Journal of Korean Forestry Society, 2012.

5. Ago, Expédit Evariste, et al. Diurnal and seasonal variability of $\mathrm{CO} 2$ fluxes over a degraded Woodland under a Sudanian climate in Northern Benin (West Africa). Geophysical Research Abstracts, 17, 2015.

6. Lee, J.A., Oh, J.-H. and Cha, D.S. Prediction of Forest Biomass Resources and Harvesting Cost Using GIS. Journal of Forest and Environmental Science, 29 (1):81-89, 2013.

7. Cohen, J. et al. Applied multiple regression/correlation analysis for the behavioral sciences. Routledge, 2013.

8. Canan, F., Yildirim, O., Yildirim Ustunel, T., Sinani, G., Hisarvant Kaleli, A., Gunes, C. and Ataoglu, A. The Relationship Between Internet Addiction and Body Mass Index in Turkish Adolescents. Cyberpsychology,Behavior, And Social Networking, $\quad$ 17(1):40-45, 2014, http://doi.org/10.1089/cyber.2012.0733

9. Vasilev, J. and Atanasova, T. Parallel Testing of Hypotheses with Statistical and Artificial Intelligence Methods : A Study on Measuring the Complacency from Education. Computer Science and Applications, 2(5):206-211, 2015.

10.IBM. SPSS, 2016, http://www01.ibm.com/software/analytics/spss/

11. Alyuda Research. Alyuda_Neurointelligence, 2016, http://www.alyuda.com/neuralnetworks-software.htm

12. Anastasova, M. Some structural changes in farms (in Bulgarian). Economics and Management of Agriculture, 53(1):16-22, 2008,http://www.jaem.info/2008/01-0308.pdf

13. Alashka, R. and Michalev, D. Methodology for analysis of economic indexes of company and business strategy for its development. Mechanics Transport Communication, 3:6872.2011,http://www.mtcaj.com/conf_2011/do k_559.pdf.

14. Gatev, K. and Gateva, N. Statistical methods in emperical surveys and business (in Bulgarian). Paradigma, Sofia, 2008.

15. Fuente, J. D. La, Santiago, J., Román, A., Dumitrache, C. and Casasanto, D. When you think about it, your past is in front of you: How culture shapes spatial conceptions of time. 2014, http://doi.org/10.1007/s13398014-0173-7.2

16. Hsiao, C.H., Yeh, S.-S. and Tsai, C.F. The Impact of Self-Complexity on Attitudes towards Online Marketing and Buying Intentions: Using the Internet Addiction as a Moderator. Marketing Review (Xing Xiao Ping Lun), 10(1):79-102, 2013.

17. Musai, M. and Darkesh, M. The Effects of Internet Addiction on Social Capital among the Youth in Tehran. International Journal of Academic Research in Economics and Management Sciences, 3(4):2226-3624, 2014, http://doi.org/10.6007/IJAREMS

18. Bulgaria, E. Executive Forest Agency, 2016, http://www.iag.bg/lang/2/index 
